\title{
Editorial
}

Gynecologic and

Obstetric Investigation

\section{European Accreditation of Endometriosis Centers of Expertise?}

Endometriosis is an estrogen-dependent gynecological disease, characterized by endometrium outside the uterus, affecting $10 \%$ of reproductive-aged women, associated with pelvic pain (dysmenorrhea, dyspareunia, nonmenstrual pelvic pain) and infertility, diagnosed by laparoscopy and classified into minimal, mild, moderate and severe stages by the American Society of Reproductive Medicine [1]. Due to a delay of 4-10 years between onset of symptoms and diagnosis, the origin of endometriosis is still not clear and treatment options have been almost the same for the last decades. Endometriosis can be treated by surgical excision or by hormonal treatment, combined with anti-inflammatory drugs. However, none of these therapeutic paradigms are curative, all have side effects, and recurrence has been reported frequently after surgery or cessation of hormonal treatment. Endometriosis impairs health-related quality of life and work productivity across countries and ethnicities, yet women continue to experience diagnostic delays in primary care [2]. The economic burden associated with endometriosis treated in referral centers is high and compares to other chronic diseases (diabetes, Crohn's disease, rheumatoid arthritis). It arises predominantly from productivity loss and is predicted by decreased quality of life [3].

In this issue of Gynecologic and Obstetric Investigation, experts from two large European countries, the UK [4] and Germany [5], report on their country's efforts to increase the quality of endometriosis care by programs of accreditation and centralization. In this editorial, we want to present the early work on centralization of endometriosis care in Denmark, in order to situate this process and the developments in Germany and the UK into a larger perspective.

In Denmark, treatment of advanced endometriosis was centralized more than 10 years ago, initiated by close collaboration between the founder of the Danish Patient's Endometriosis Society Lone Hummelshoj and the last author of this editorial. After development of surgical techniques through repeated visits to established European centers, the need for sub-specialization was evident, but this goal seemed far away, since many colleagues perceived endometriosis as a disseminated disease resistant to surgical treatment. The possibilities for dialogue between medical doctors and decision-makers in the political and administrative system were limited, but the patients' representative, Lone Hummelshoj had the formal authority to motivate the Minister of Health to invite herself and A.F. to a meeting, where the idea of two national referral centers was put forward and acknowledged. Formal guidelines from the Danish Health and Medicines Authority on centralized treatment of advanced disease then followed in 2001. Implementation occurred over the 
next few years, since patients and referring colleagues experienced the benefits of systematic diagnosis and treatment. The process was aided by the legal possibility in Denmark allowing general practitioners to refer their patients directly to specialist centers. The Danish Endometriosis Patients' Association made a nation-wide effort by informing their members at regional meetings, and by individual counseling in cases where the new possibilities had not yet been taken into account. Finally, guidelines from the Danish Health and Medicines Authority soon developed into rather detailed rules with legal character, covering almost all specialties in both the public and private healthcare systems. In concert, these factors imply that treatment of advanced endometriosis outside the frame of the two specialist centers has vanished.

Lessons learned from the Danish example include the potential benefits from collaboration between gynecologists and Endometriosis Patients' Associations when new healthcare strategies are needed in the political and administrative system. In addition, the reputation of the nominated referral centers represents a cornerstone for subsequent professional implementation, and formal accreditation should be today's standard.

The centralization of care for patients with advanced endometriosis in Denmark, the UK and Germany is not surprising in this time of modern medicine, with increasing awareness about the quality of care, patient-related outcomes and patient-centered approaches, also in the field of endometriosis [6-9]. Over the years, the concept of 'endometriosis centers of excellence' has evolved to 'endometriosis centers of expertise' [9]. Such centers/networks should ideally comprise a multidisciplinary team approach with specialists who have undergone specific training in endometriosis, advanced surgeons with a high caseload of managing deep endometriosis, ready access to an endometriosis organization with substantial input on behalf of women and a track record of commitment to collaborative management and research [9]. As laparoscopic surgery will likely continue to be pivotal in the management of women with endometriosis, accreditation should be focused on the training and expertise of laparoscopic surgeons [9]. Whilst it is impractical that all women with endometriosis are currently managed in a center/network of expertise, those with higher stage of disease and/or more intractable clinical problems should receive care from such a center or network [9]. Indeed, centralized and multidisciplinary care is especially important from women who have deep endometriosis with colorectal and/or urological extension. Surgical expertise is critical, complex, and related to variable complication and recurrence rates. The lack of standardization in reporting clinical outcome variables after surgery for deep endometriosis has recently been recognized in two systematic reviews on this topic $[10,11]$. In order to improve standardization and quality of care, the establishment of endometriosis centers of expertise in Denmark, the UK and Germany should inspire other European countries to follow the same path, ideally with a European system of accreditation monitored by the European Board and College of Obstetrics and Gynecology. The principles are clear: a limitation of the number of centers per country where women with advanced and deep endometriosis can be treated, in order to increase the expertise per center and per gynecologist, on the condition that these centers of expertise develop an obligatory and transparent system [9] to record clinical outcome data with respect to symptom relief (pain, infertility), quality of life, complications and recurrences. As in other areas of medicine and surgery, such progress can be achieved by a national and European focus on effective acquisition of clinical data, based on standardizing the structure of electronic health record data in patient files, including variables for quality measurement related to both process and outcome [12]. Such standardization may then allow regional, national and international data sharing, which will promote collaborative approaches to quality improvement with respect to safety, effectiveness, efficiency and cost [12]. However, such initiatives can only be successful depending on the participation of frontline clinicians [12].

Prof. Thomas D'Hooghe, Leuven

Prof. Axel Forman, Aarhus

References

1 American Society of Reproductive Medicine: Revised American Society for Reproductive Medicine classification of endometriosis: 1996. Fertil Steril 1997;67:817-821.

2 Nnoaham KE, Hummelshoj LH, Webster P, D’Hooghe T, De Cicco Nardone F, De Cicco Nardone C, Jenkinson C, Kennedy SH, Zondervan KT, on behalf of the WERF GSWH Consortium: Impact of endometriosis on quality of life and work productivity: a multi-centre study across 10 countries. Fertil Steril 2011;96:366-373.e8.

- 3 Simoens S, Dunselman G, Dirksen C, Hummelshoj L, Bokor, A, Brandes I, Brodszky V, Canis M, Colombo GL, DeLeire T, Falcone T, Graham B, Halis G, Horne A, Kanj O, Kjer JJ, Kristensen J, Lebovic D, Mueller M, Vigano P, Wullschleger M, D'Hooghe T: The burden of endometriosis: costs and quality of life of women with endometriosis treated in referral centres. Hum Reprod 2012;27:1292-1299. 
4 Saridogan E, Byrne D: The British Society for Gynaecological Endoscopy Endometriosis Centres Project. Gynecol Obstet Invest 2013, E-pub ahead of print.

5 Ebert AD, Ulrich U, Keckstein J, Müller M, Schindler AE, Sillem M, Tinneberg HR, De Wilde RL, Schweppe KW: Implementation of certified endometriosis centers: 5-year experience in German-speaking Europe. Gynecol Obstet Invest 2013, E-pub ahead of print.

-6 D'Hooghe TM, Hummelshoj L: Multi-disciplinary centres/networks of excellence for endometriosis management and research: a proposal. Hum Reprod 2006;21:2743-2748.
7 Dancet EA, Ameye L, Sermeus W, Welkenhuysen M, Nelen WL, Tully L, De Bie B, Veit J, Vedsted-Hansen H, Zondervan KT, De Cicco C, Kremer JA, Timmerman D, D'Hooghe TM: The ENDOCARE Questionnaire (ECQ): a valid and reliable instrument to measure the patient-centeredness of endometriosis care in Europe. Hum Reprod 2011;26:2988-2999.

$\checkmark 8$ Dancet EA, Apers S, Kluivers KB, Kremer JA, Sermeus W, Devriendt C, Nelen WL, D'Hooghe TM: The ENDOCARE questionnaire guides European endometriosis clinics to improve the patient: centeredness of their care. Hum Reprod 2012;27:3168-3178.

-9 Johnson NP, Hummelshoj L, for the World Endometriosis Society Montpellier Consortium: consensus on current management of endometriosis. Hum Reprod 2013;28:15521568 .
10 Meuleman C, Tomassetti C, D'Hoore A, Van Cleynenbreugel B, Penninckx F, Vergote I, D'Hooghe TM: Surgical treatment of deeply infiltrating endometriosis with colorectal involvement. Hum Reprod Update 2011;17: 311-326.

11 De Cicco C, Corona R, Schonman R, Mailova K, Ussia A, Koninckx P: Bowel resection for deep endometriosis: a systematic review. BJOG 2011;118:285-291.

12 Greenberg CC: Promoting quality surgical care. The next steps. JAMA 2013;309;827828. 